\title{
ACCURACY EVALUATION OF VARIOUS SATELLITE IMAGERY PRODUCTS FOR LARGE SCALE TOPOGRAPHIC MAPPING
}

\author{
Nidhi Gahlot, Mrinmoy Dhara*, Ganesh Prusty \\ Defence Terrain Research Laboratory (DTRL), Defence Research and Development Organization, New Delhi \\ mrinmoy0907@gmail.com
}

Commission V, WG V/7

KEY WORDS: Satellite imagery products, Accuracy assessment, Cartosat, Topographic mapping, DEM

\begin{abstract}
:
DEM and ortho-imageries are building blocks for topographic mapping and satellite imageries are prime source of data for inaccessible terrain. When the required mapping scale is of the order 10k or higher, the accuracy needed is also of higher order. It becomes imperative to evaluate the accuracy of available high resolution DEMs and corresponding imageries to provide quality products for mapping. The present study is encouraged by the fact that not every place of our earth is accessible, so an assessment of satellite data products is required for precise mapping. Here, the accuracy assessment has been carried out in terms of RMSE, SD, CE90 and LE90 of various products viz. Carosat-1, Cartosat-2E, Worldview-2 (WV), Vricon, Pleiades, ALOS-World-3D (AW3D) ASTER, SRTM with Yahoo image. GCPs acquired by DGPS field survey were used to evaluate the products. The results have demonstrated that Vricon 0.5m ortho-image provides the best RMSE (3.42) and CE90 (4.65); however, WV and Vricon DEM turns out to be best with RMSE of $2.20 \mathrm{~m}$ and $2.90 \mathrm{~m}$ respectively. Both products are suitable for large scale topographic mapping. The data can be used for inaccessible terrain where GCPs are not available. However, Cartosat-1 and Cartosat-2E can be used where good GCPs are available. The outcome of study can be used for planning of data suitability for scale variant mapping and inaccessible terrain mapping.
\end{abstract}

\section{INTRODUCTION}

Accurate geo-spatial information on Digital Elevation Models and ortho-rectified images are crucial for mapping products. Remote sensing satellite imageries are an important source of spatial data to prepare the base for extraction of geo-spatial intelligence required in the maps particularly for inaccessible terrain (Anderson, Ryan, Sonntag, Kavvada, \& Friedl, 2017; Corbane et al., 2017; Li, 1998; Ottichilo \& Khamala, 2010; Radhadevi et al., 2009, 2010). Traditionally, maps were prepared by plain table field surveys and were updated manually which included larger effort and higher costs (Rayburg, Thoms, \& Neave, 2009; Singh, Gupta, Snehmani, Bhardwaj, \& Ganju, 2015). The potential of satellite imagery has exponentially increased with the recent developments of space technology and it provides a cost-effective alternative to traditional methods. The elevation and positional accuracy of the satellite data is also progressively increasing.

High resolution DEM and ortho-rectified satellite images are vital to depict the basic information about the terrain relief with the natural and man-made features while attempting large scale mapping especially in inaccessible terrains (Amin Khan, Akhter, \& Ahmad, 2013; Baral, Das, Saraf, Borgohain, \& Singh, 2016; Li, 1998; Ottichilo \& Khamala, 2010; Radhadevi et al., 2009, 2010; Vaze, Teng, \& Spencer, 2010). Fortunately, the present and future planned earth imaging satellites provides and will be providing strong geometric capabilities that are motivating to mapping community for large scale topographic mapping of even the hardest of inaccessible terrain present on surface.

* Corresponding Author
Previous studies were directed towards potential of remote sensing satellite data products for mapping in general (Drachal \& Kawel, 2016; Li, 1998; Vaze et al., 2010; Wilson, 2012) or large scale mapping (Fraser, Baltsavias, \& Gruen, 2002; Ottichilo \& Khamala, 2010; Radhadevi et al., 2010) in particular.

Studies have been for extraction of high resolution DEM and their accuracy assessment using Very high Resolution (VHR) optical (Aguilar, Aguilar, Agüera, \& Sánchez, 2007; Habib et al., 2017) and SAR (Rizzoli et al., 2017) based satellites. All these studies are in moderately sloping and regular topography areas. Efforts have been made for accuracy of Cartosat Dem over a more complex terrain viz. Himalayas (Giribabu, Kumar, Mathew, Sharma, \& Krishna Murthy, 2013; Radhadevi et al., 2010). Studies (Paul, Huggel, \& Kääb, 2004; Singh, Snehmani, et al., 2015) have demonstrated extensive use of VHR optical satellite ortho imageries and DEM in high relief terrain.

The major challenge for the optical imaging system lies in the modeling of extremely inclined formations with gradient $>40^{\circ}$ (Müller, Gärtner-Roer, Thee, \& Ginzler, 2014). So, there arises a need of proper assessment of all possible available commercial VHR satellite data products viz. VRICON, ALOS world 3D (AW3D), Worldview 2, Pléiades etc to arrive at a conclusion that which ortho-product with its corresponding DEM is able to model the high gradient area in combination to low and moderate gradients more accurately.

\section{STUDY AREA}

As discussed, there is a need of authenticity of DEM and satellite ortho products in highly rugged and undulating terrain with respect to gradient within small spatial extent. For this reason, the study area selected is part of Uttrakhand state in India i.e. Rishikesh and its surroundings. The study area is situated in the foothills of Himalayas under the regime of Sivaliks. The study area roughly covers an area of 110 sq. Km.. 


\subsection{Geological setup}

Geologically this area is a hotspot of tectonic activities. The main boundary thrust pass through the study area marking the boundary between the Sivaliks and Lower Himalayas. This is the reason that within a small spatial extent the terrain gradient changes from nearly 0 to $70^{\circ}$. Moreover, the relief also changes from mere 350 meters to nearly 1600 meters above sea level. This area before switching on Himalayas is covered with partially Sivalik Sandstone and Doon gravels. The holy river of Ganges cutting through the Himalayas, enters here less tectonically complicated area of Sivaliks and subsequently Gangatic planes. Geomorphologically, the area comprises of suddenly high rising hills due to transition zone of sivaliks and Himalayas. Lithologically, apart from Sivaliks (Subathu) sandstone, it comprises Shale mixed dolomitic limestones and phyllites of Krol, tal and Chandpur formations respectively. Structuraaly this area comprises of the autochthonous units of Sivaliks and Simla Slates, Krol and Garhwal nappe (Bassi, 1968).

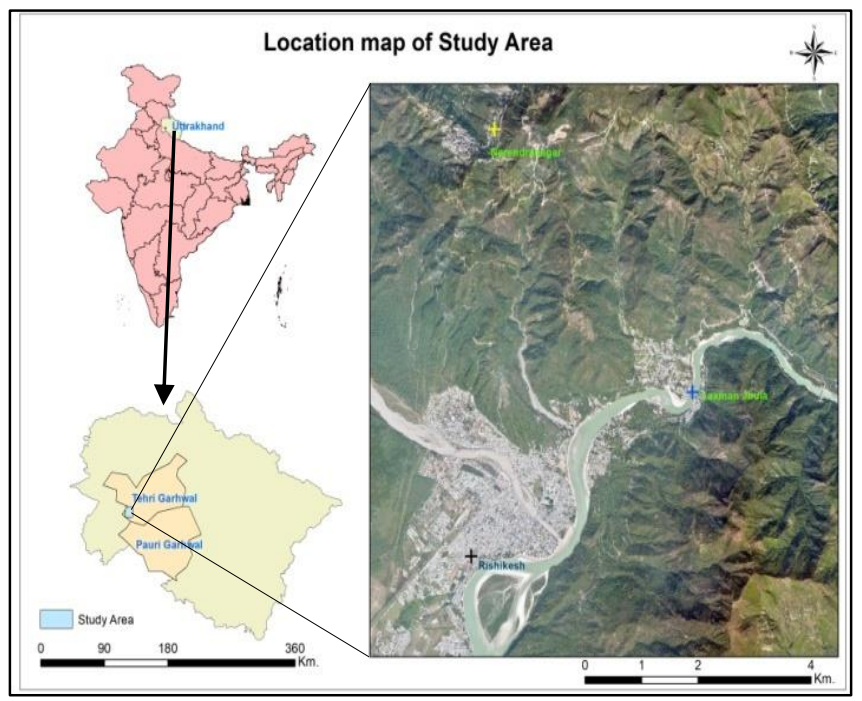

Figure 1 Study area Rishikesh, Uttrakhand.

(Satellite product - Natural color composite $\{\mathrm{NCC}\}$ of Vricon Ortho product)

\section{METHODOLOGY AND DATA USED}

\subsection{Data used}

3.1.1 Input Data: The data products used for accuracy evaluation are open source DEM and corresponding imageries, commercially available stereo data and DEM with corresponding ortho-images. The details of input data are given in Table 1.

3.1.2 Reference Data: The study area was surveyed by DTRL team with DGPS to acquire good control points in terms of planimetry (XY) and elevation (Z) both. A total of 56 stratified GCPs were collected during 5 days survey using Trimble Geo7 GCP receiver. Further, post-processing has been done using Trimble ${ }^{\circledR}$ GPS Pathfinder office $\odot$ software and observations were differentially corrected using base station receiver data.
The accuracy of the GCPs has been ascertain by comparing four field observation with SOI GCPs in the region and it is found that field observation have centimetre level of accuracy. The projection and datum of the field collected GCPs are UTM WGS84 and MSL respectively. The distribution of GCPs is depicted in figure- 2 .

\begin{tabular}{|l|c|c|c|}
\hline \multirow{2}{*}{ Satellite Products } & \multicolumn{2}{|c|}{$\begin{array}{c}\text { Spatial Resolution } \\
(\mathrm{m})\end{array}$} & \multirow{2}{*}{ DOP of Image } \\
\cline { 2 - 3 } & Image & DEM & \\
\hline Cartosat 1\# & 2.5 & 10 & $15 / 03 / 2011$ \\
Worldview 2 $^{\#}$ & 0.5 & 2 & $17 / 02 / 2012$ \\
Vricon+ & 0.5 & 0.5 & $28 / 03 / 2018$ \\
Pleiades $^{+}$ & 0.5 & 5 & -- \\
AW3D $^{+}$ & 5 & 10 & -- \\
Cartosat- 2E $^{+}$ & 0.6 & NA & $29 / 03 / 2018$ \\
ASTER $^{\wedge}$ & 15 & 30 & $14 / 05 / 2012$ \\
Yahoo \& SRTM $^{\wedge}$ & 0.5 & 30 & $28 / 04 / 2014$ \\
\hline
\end{tabular}

Table 1 ( ${ }^{\#}$ Commercial stereo data processed at DTRL, ${ }^{+}$Commercial product, ${ }^{\wedge}$ Open sourcewww.earthexplorer.usgs.gov.in, DOP- Date of Pass)

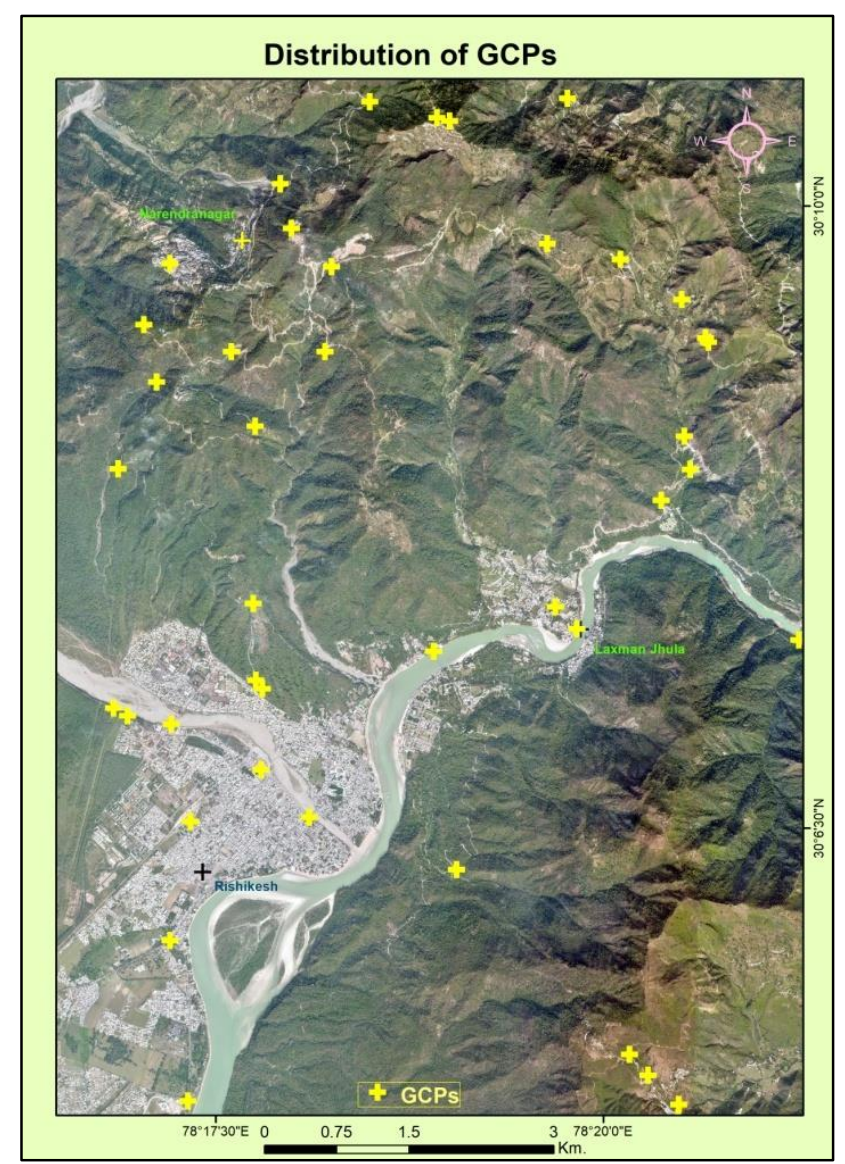

Figure 2 Distribution of GCPs in the study area.

(Background - NCC of Vricon true ortho product)

\subsection{Methodology}

The methodology adopted to assess the accuracy of various available satellite data products (DEM and corresponding ortho imageries) to find out their suitability for large scale mapping is 
depicted with following flow chart and briefed in subsequent sections:

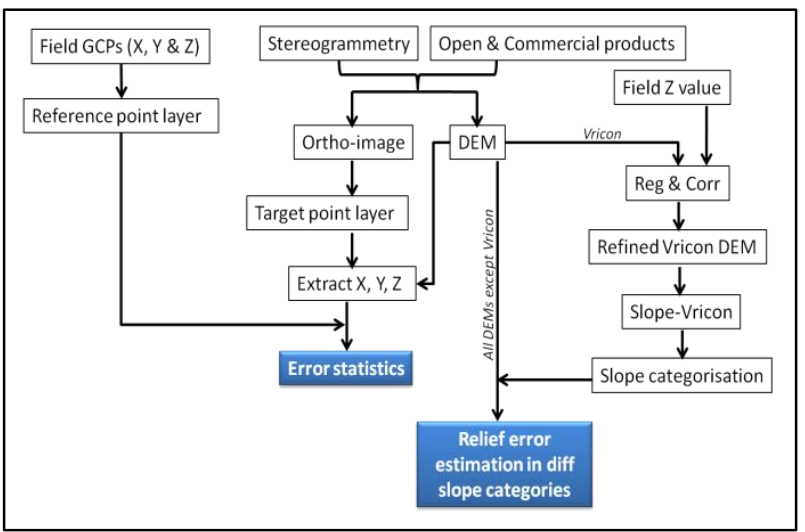

Figure 3 Flow chart depicting the methodology adopted during the study.

3.2.1 Stereogrammetry: Ortho-engine module of Rolta Geomatica 2012 software has been used for the stereogrammetric processing of the Cartosat-1 and Worldview-2 stereo data(PCI Geomatics Enterprise Inc, 2012). The DEM have been reconstructed based of RPCs provided with satellite data and no bundle adjustment has been done using field GCPs. However, an attempt has been made to refine the RPCs of Cartosat-1data obtaining full GCPs from Vricon true-ortho image and corresponding DEM (Product with height accuracy). The projection of the final products is UTM, WGS84.

3.2.2 Defining reference: A reference point layer by plotting all 56 field GCPs has been generated. Further, all images under consideration for accuracy assessment have been reviewed with visual inspection and a total of 32 GCPs were finalised which are identifiable in all considered spatial resolution. All the products were initially assessed for $\mathrm{X}, \mathrm{Y}$ and $\mathrm{Z}$ at these 32 locations.

It is inferred from the error statistics that Vricon true ortho has the least error. Hence, its corresponding DEM has been further refined / improved by applying regression and correlation using field observations. This refined product is further used as reference to evaluate the vertical accuracy in different slope categories of the all remaining products.

3.2.3 Horizontal and vertical accuracy assessment: GCP locations have been identified on all the considered orthoimageries and corresponding target layers have been generated. Latitude and longitude (X \& Y) of each data have been extracted through target layer using Arc-GIS 10.3. Target coordinates have been further compared with reference coordinates to compute error statistics in terms of Mean error (ME), Standard deviation (SD), Root Mean Square error (RMSE) and Circular error (CE90). For planimetric error estimation, Haversine formula (1) was used as it incorporates the effect of earth's eccentricity on the straight Euclidean distance even in small range (Kettle, 2017). It estimates the great-circle distance between two points on the surface of a sphere.

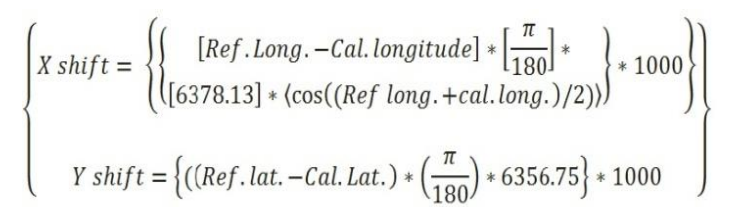

Further, same target point layers have been used to extract elevation values of the corresponding DEMs using Arc toolbox and assessed with respect to field observations in terms of ME, SD, RMSE and Linear error (LE90).

To ascertain the relief accuracy in changing slope, slope map has been created based on refined Vricon DEM and categorized in three slope categories i.e. less than $15^{\circ}, 15^{\circ}-30^{\circ}$ and above $30^{\circ}$. Vertical accuracy of all the other products with reference to refined Vricon has been assessed thereafter.

\section{RESULTS AND DISCUSSION}

The research undertaken by the earlier workers has proven that the mode and quality of terrain representation primarily depends on the spatial resolution of the DEM and ortho-rectified imagery. The present study was carried out for evaluation of vertical accuracy and horizontal accuracy of all the satellite based imagery products with reference to the control points acquired through the topographic survey. The statistical indices used for the purpose are Min-Max error range, Mean Error, Root Mean Square Error (RMSE), LE 90 and CE 90. Before accuracy evaluation, it is ensured that the DEM should have very good correspondence with the Ortho-images, preferably both the products are from same source. Here, the data source can be categorized into two types namely, (i) reconstruction of DEM using stereo-grammetry principles and corresponding Ortho-image such as Cartosat-1 and WV 2; (ii) the products available off-the-selves (Cartosat-2E, Vricon, Defence Airbus, AW3D) including open domain products (SRTM, Yahoo Image). A close study of all the products i.e. in-house constructed and COTS was done for horizontal and vertical accuracy. To evaluate the accuracy of the above products, 56 reference points or GCPs were collected during the field survey; only 32 points could be used for the assessment purposes which are identifiable in all the considered ortho imageries. The general elevation values ranges between 340 to 1650 meters in all the datasets. The mean error, standard deviation and RMSE were calculated using Haversine distance formula for resultant spatial shift. The estimated error statistics are depicted in the table 2 and table 3 .

The stereo images of Cartosat and WV were used to generate DEM and Ortho-image products; whereas the commercial offthe-shelve products of Cartosat-2E, AW3D, DA (plieades) and Vricon Ortho-rectified data were evaluated directly. The open source dataset of Yahoo, SRTM and ASTER were downloaded from USGS website and accuracy assessment was carried out. A close inspection of Table 2 revealed that Vricon products have demonstrated the best horizontal accuracy with 3.42 RMSE and 4.65 CE90. The ortho-rectified images of WV products produced the results with slightly higher RMSE and CE90 i.e. 4.75 and 6.76 respectively. It is also seen that the RPC based ortho-rectified Cartosat-1 image which has 118.64 RMSE and 129.06 CE90 got rectified after incorporation of GCPs from Vricon product as reference viz. RMSE of 6.99 and CE90 of 9.42. However, Cartosat-2E with 2.69, $6.69 \& 8.66$ of SD, RMSE and CE90 provides better accuracy than bundle adjusted Cartosat-1 imagery; non-availability of corresponding DEM limits its utility. It is also observed that among the open source dataset, Yahoo imagery provides the most accurate results with RMSE of 5.80 and CE90 of 9.80 . 


\begin{tabular}{|l|l|l|l|l|}
\hline Satellite product & Mean & SD & RMSE & CE90 \\
\hline Cartosat & 118.42 & 7.36 & 118.64 & 129.06 \\
Cartosat(GCP) & 5.42 & 4.49 & 6.99 & 9.42 \\
Worldview & 4.25 & 2.15 & 4.75 & 6.76 \\
Vricon & 2.96 & 1.74 & 3.42 & 4.65 \\
Pleiades & 4.66 & 7.31 & 8.58 & 6.18 \\
AW3D & 4.99 & 2.79 & 5.69 & 7.85 \\
Cartosat 2E & 6.16 & 2.69 & 6.69 & 8.66 \\
ASTER & 17.32 & 10.30 & 20.07 & 26.06 \\
Yahoo & 4.51 & 3.70 & 5.80 & 9.80 \\
\hline
\end{tabular}

Table-2: Mean , Standard deviation (SD), Root mean square error (RMSE) and CE90 of Resultant circular shift for all data products

\begin{tabular}{|l|l|l|l|c|}
\hline Satellite product & Mean & SD & RMSE & CE90 \\
\hline Cartosat & -40.04 & 6.91 & 40.61 & 43.07 \\
Cartosat(GCP) & 0.43 & 6.21 & 6.13 & 8.58 \\
WorldView & 0.043 & 2.23 & 2.20 & 4.45 \\
Vricon & 1.06 & 2.75 & 2.90 & 5.98 \\
Pleiades & 3.21 & 7.78 & 8.30 & 22.68 \\
AW3D & -3.47 & 3.87 & 5.16 & 5.78 \\
ASTER & 5.43 & 16.10 & 16.75 & 45.23 \\
SRTM & 0.99 & 10.38 & 10.27 & 16.43 \\
\hline
\end{tabular}

Table 3 - Mean, SD, RMSE and subsequent LE90 of Vertical error for all data products

The analysis of the vertical accuracy results and error statistics is presented in Table 4. Here also, it is observed that Vricon DEM has provided the best vertical accuracy with RMSE of 2.11 , followed by worldview DEM with $2.20 \mathrm{~m}$. While the errors were estimated in terms of LE90; it is observed that WV DEM has better consistency in comparison to Vricon DEM with the values of 4.45 and 5.98 respectively. Moreover, the LE90 value of AW3D DEM is also comparable with above and is 5.78 only. The enhancement of SD, RMSE and LE90 in Cartosat products after bundle adjustment is significant as depicted in table 3 . The accuracy has improved in terms of LE 90 from 43.07 to 8.58 .

The rolling topography of Rishikesh study area is characterized by a variety of slope categories represented by plain topography, moderate sloppy areas and high relief terrain. To ascertain vertical accuracy in changing slope all the products were assessed with respect to different slope categories. The result of above accuracy assessment has ascertained that Vricon is providing the products more near to the real ground. Hence, to overcome the meagre error, the regression analysis between field elevation data (DGPS Survey) and image observed data (Vricon data) was carried out and the Vricon DEM was refined accordingly. Same has been further used as reference for slope categorisation. A slope map was created using refined Vricon DEM and categorised in three slope category i.e. $0-15^{0}$ (Low), $15^{0}-30^{\circ}$ (Moderate) and above $30^{\circ}($ High). During the field investigation care was taken for stratified sampling of GCP collection with at least 10 sample points from each slope category. The accuracy assessment results in all the 3 slope categories are depicted in table 4 and table 5 for planimetric and vertical accuracy respectively. The analysis results demonstrated that the Vricon and WV products are having better positional accuracy values in all the three categories of slope. It is also observed that the moderate terrain slope areas are relatively more accurate in bundle adjusted Cartosat DEM in comparison to low and high slope terrain with RMSE of 4.53.

\begin{tabular}{|l|c|c|c|c|c|c|}
\hline $\begin{array}{l}\text { Slope } \rightarrow \\
\text { Categories }\left(^{\circ}\right)\end{array}$ & \multicolumn{2}{|c|}{ Less than 15 } & \multicolumn{2}{c|}{$15-30$} & \multicolumn{2}{c|}{$30+$} \\
\hline $\begin{array}{l}\text { Satellite } \\
\text { Products } \downarrow\end{array}$ & SD & RMSE & SD & RMSE & SD & RMSE \\
\hline Cartosat & 5.55 & 115.44 & 7.44 & 118.52 & 6.77 & 125.44 \\
Cartosat(GCP) & 5.46 & 7.49 & 2.15 & 4.53 & 4.24 & 7.54 \\
WV & 2.19 & 4.41 & 2.31 & 5.96 & 1.31 & 3.87 \\
Vricon & 1.63 & 2.89 & 3.85 & 5.59 & 2.04 & 4.61 \\
Pleiades & 1.65 & 3.02 & 11.67 & 12.40 & 2.51 & 5.54 \\
AW3D & 2.97 & 5.43 & 2.28 & 5.82 & 2.69 & 6.54 \\
ASTER & 13.75 & 23.74 & 7.98 & 17.80 & 3.84 & 15.02 \\
SRTM & 3.36 & 5.22 & 4.52 & 6.17 & 2.92 & 6.46 \\
\hline
\end{tabular}

Table-4: Standard deviation and RMSE in planimetric direction in different slope categories.

\begin{tabular}{|l|l|l|l|l|l|l|}
\hline $\begin{array}{l}\text { Slope } \rightarrow \\
\text { Categories( }\left(^{\circ}\right)\end{array}$ & \multicolumn{2}{|l|}{ Less than 15 } & \multicolumn{2}{c|}{$15-30$} & \multicolumn{2}{c|}{$30+$} \\
\hline $\begin{array}{l}\text { Satellite } \\
\text { Products } \downarrow\end{array}$ & SD & RMSE & SD & RMSE & SD & RMSE \\
\hline Cartosat & 5.22 & 41.41 & 6.90 & 34.50 & 9.71 & 31.34 \\
Cartosat(GCP) & 4.35 & 4.49 & 8.25 & 9.17 & 7.41 & 7.09 \\
WV & 2.90 & 2.83 & 1.07 & 1.14 & 1.19 & 1.10 \\
Vricon & 1.63 & 1.70 & 3.03 & 3.32 & 2.84 & 2.67 \\
Pleiades & 2.92 & 3.28 & 9.07 & 8.78 & 9.96 & 11.03 \\
AW3D & 3.35 & 4.44 & 2.08 & 3.86 & 6.92 & 8.33 \\
ASTER & 14.05 & 14.25 & 18.59 & 18.42 & 15.73 & 17.81 \\
SRTM & 9.00 & 8.87 & 9.76 & 10.06 & 14.63 & 13.42 \\
\hline
\end{tabular}

Table-5: Vertical error statistics in different slope categories

Further, the vertical error estimation with respect to change in slope has also been carried out with the slope classification data. It is observed that RPC based WV DEM with 1.1m RMSE has the best quality in high slope areas and Vricon DEM also has good accuracy with $2.67 \mathrm{~m}$ RMSE in high slope. It is evident that WV and Vricon DEMs are consistent in quality in all slope categories. Significant improvement is seen in the GCP based Cartosat DEM where high slopes are having better accuracy than moderate slope. However, the errors in SRTM and ASTER DEMs are increasing with increase in slope. AW3D and Pleiades DEMs have better accuracy in low slope but the error increases with higher rate in high slopes with RMSE of $8.33 \mathrm{~m}$ and $11.03 \mathrm{~m}$ respectively.

\section{CONCLUSION}

Ortho-rectified satellite imageries with corresponding DEM are being used as base for topographic mapping and they are the prime input for geo-spatial framework (Erdogan, Eker, Yilmaz, $\&$ Aksu, 2004) . The present study has evaluated the accuracy of the available satellite data products (Ortho-image and corresponding DEM) with an objective of generating mapping products for inaccessible terrain. The Rishikesh area with varied topography is selected as test site and all the satellite products were evaluated with respect to GCP references available with DTRL. 
The results demonstrated that the freely available mapping products are lacking resolution and their accuracy does not match for high precision mapping. Hence, the same cannot be used in geo-spatial framework for strategic planning. The Cartosat-1 DEM generated using RPC is also off by $118 \mathrm{~m}$ (RMSE) in palnimetry. However, Cartosat-2E imagery provides good accuracy with RMSE of $6.69 \mathrm{~m}$ but corresponding matching DEM is not available. It is observed that RPC based Cartosat-1 product can be improved significantly with the use of good GCPs during bundle adjustment.

Among commercially available satellite data products, Vricon products are found to be most accurate. Moreover, the WV products generated through stereogrammetry are also comparable and both can be used for large scale topographic mapping. The data can be used for inaccessible terrain where GCPs are not available. However, Cartosat-1 and Cartosat-2E can be used where good GCPs are available.

\section{ACKNOWLEDGEMENT}

The authors are thankful to the Dr. L.K. Sinha (Director, DTRL) and Dr. M.R. Bhutiyani (Former Director, DTRL) for their encouragement to carry out the study. The authors also grateful to the DTRL team for the DGPS field survey carried out by Shri Pratik Chaturvedi, Shri Michael Hembrom, Shri Juby Thomas and Shri Rakesh Kumar. Authors would like to extend their gratitude to M/s Antrix Corporation, Department of Space, Government of India for facilitating sample satellite data products from all the sources.

\section{REFERENCES}

Aguilar, M., Aguilar, F., Agüera, F., \& Sánchez, J. A. (2007). Geometric accuracy assessment of QuickBird basic imagery using different operational approaches. Photogrammetric Engineering \& Remote Sensing, 73(12), 1321-1332. https://doi.org/10.14358/PERS.73.12.1321

Amin Khan, K., Akhter, G., \& Ahmad, Z. (2013). Integrated geoscience databanks for interactive analysis and visualization. International Journal of Digital Earth, 6(SUPPL.2), 41-49. https://doi.org/10.1080/17538947.2011.638990

Anderson, K., Ryan, B., Sonntag, W., Kavvada, A., \& Friedl, L. (2017). Earth observation in service of the 2030 Agenda for Sustainable Development. Geo-Spatial Information Science, 20(2), 77-96. https://doi.org/10.1080/10095020.2017.1333230

Baral, S. S., Das, J., Saraf, A. K., Borgohain, S., \& Singh, G. (2016). Comparison of Cartosat, ASTER and SRTM DEMs of Different Terrains. Asian Journal of Geoinformatics, 16(1).

Bassi, U. K. (1968). Geology of the area between River Ganga and River HUINL (East of Rishikesh) District Pauri Garhwal, U.P. University of Roorkee (IIT Roorkee). Retrieved from http://shodhbhagirathi.iitr.ac.in:8081/jspui/image/pdf/web/view er.html?file=/jspui/bitstream/123456789/10141/1/GED105032. pdf

Corbane, C., Pesaresi, M., Politis, P., Syrris, V., Florczyk, A. J., Soille, P., ... Rodriguez, D. (2017). Big earth data analytics on
Sentinel-1 and Landsat imagery in support to global human settlements mapping. BIG EARTH DATA, 4471(December), 127. https://doi.org/10.1080/20964471.2017.1397899

Drachal, J., \& Kawel, A. K. (2016). Determining the suitability of different digital elevation models and satellite images for fancy maps. An example of Cyprus. International Archives of the Photogrammetry, Remote Sensing and Spatial Information Sciences - ISPRS Archives, 41(July), 591-597. https://doi.org/10.5194/isprsarchives-XLI-B4-591-2016

Erdogan, M., Eker, O., Yilmaz, A., \& Aksu, O. (2004). Orthorectification of SPOT images with the same-pass constraints. In XXth ISPRS Congress (pp. 12-23). Instanbul, Turkey: ISPRS. Retrieved from http://www.isprs.org/proceedings/XXXV/congress/comm4/pape rs/415.pdf

Fraser, C. S., Baltsavias, E., \& Gruen, A. (2002). Processing of Ikonos imagery for submetre 3D positioning and building extraction. ISPRS Journal of Photogrammetry and Remote Sensing, 56(3), 177-194. https://doi.org/10.1016/S09242716(02)00045-X

Giribabu, D., Kumar, P., Mathew, J., Sharma, K. P., \& Krishna Murthy, Y. V. N. (2013). DEM generation using Cartosat-1 stereo data: Issues and complexities in Himalayan terrain. European Journal of Remote Sensing. https://doi.org/10.5721/EuJRS20134625

Habib, A., Akdim, N., El Ghandour, F. ezzahra, Labbassi, K., Khoshelham, K., \& Menenti, M. (2017). Extraction and accuracy assessment of high-resolution DEM and derived orthoimages from ALOS-PRISM data over Sahel-Doukkala (Morocco). Earth Science Informatics, 10(2), 197-217. https://doi.org/10.1007/s12145-017-0287-5

Kettle, S. (2017). Distance on a sphere: The Haversine Formula. Retrieved from https://community.esri.com/groups/coordinatereference-systems/blog/2017/10/05/haversine-formula

Li, R. (1998). Potential of high-resolution satellite imagery for national mapping products. PHOTOGRAMMETRIC ENGINEERING AND REMOTE SENSING, 64(12), 1165-1170. Retrieved from http://apps.webofknowledge.com/full_record.do?product=UA\& search_mode=AdvancedSearch\&qid=13\&SID=N2dYKzaT2gB1 $\mathrm{mkZoFe} 1 \&$ page $=2 \&$ doc $=11 \&$ cacheurlFromRightClick=no

Müller, J., Gärtner-Roer, I., Thee, P., \& Ginzler, C. (2014). Accuracy assessment of airborne photogrammetrically derived high-resolution digital elevation models in a high mountain environment. ISPRS Journal of Photogrammetry and Remote Sensing, 98, 58-69. https://doi.org/10.1016/j.isprsjprs.2014.09.015

Ottichilo, W., \& Khamala, E. (2010). Map Updating Using High Resolution Satelite Imagery a Case of the Kingdom of Swaziland. The International Archives of the Photogrammetry, Remote Sensing and Spatial Information Sciences, XXXIV(6), 89-92. Retrieved from http://www.isprs.org/proceedings/XXXIV/6W6/papers/khamala_ottichilo.pdf 
The International Archives of the Photogrammetry, Remote Sensing and Spatial Information Sciences, Volume XLII-5, 2018 ISPRS TC V Mid-term Symposium "Geospatial Technology - Pixel to People", 20-23 November 2018, Dehradun, India

Paul, F., Huggel, C., \& Kääb, A. (2004). Combining satellite multispectral image data and a digital elevation model for mapping debris-covered glaciers. Remote Sensing of Environment, 89(4), 510-518.

https://doi.org/10.1016/j.rse.2003.11.007

PCI Geomatics Enterprise Inc. (2012). Rolta Geomatica 2012 User Manual.

Radhadevi, P. V, Nagasubramanian, V., Mahapatra, A., Solanki, S. S., Sumanth, K., \& Varadan, G. (2009). Potential of HighResolution Indian Remote Sensing Satellite Imagery for Large Scale Mapping. ISPRS Archives, XXXVIII(January 2009).

Retrieved from

http://www.isprs.org/proceedings/XXXVIII/1_4_7-

W5/default.aspx

Radhadevi, P. V, Solanki, S. S., Nagasubramanian, V., Mahapatra, A., Reddy, D. S., Jyothi, M. V, ... Varadan, G. (2010). New Era of Cartosat Satellites for Large Scale Mapping. Photogrammetric Engineering \& Remote Sensing, 76(9), 10311040.

Rayburg, S., Thoms, M., \& Neave, M. (2009). A comparison of digital elevation models generated from different data sources. Geomorphology, 106(3-4), 261-270.

https://doi.org/10.1016/j.geomorph.2008.11.007

Rizzoli, P., Martone, M., Gonzalez, C., Wecklich, C., Tridon, D. B., Bräutigam, B., ... Moreira, A. (2017). Generation and performance assessment of the global TanDEM-X digital elevation model. ISPRS Journal of Photogrammetry and Remote Sensing, 132, 119-139.

https://doi.org/https://doi.org/10.1016/j.isprsjprs.2017.08.008

Singh, M. K., Gupta, R. D., Snehmani, Bhardwaj, A., \& Ganju, A. (2015). Effect of sensor modelling methods on computation of 3-D coordinates from Cartosat-1 stereo data. Geocarto International, 31(5), 506-526. https://doi.org/10.1080/10106049.2015.1059900

Singh, M. K., Snehmani, Gupta, R. D., Bhardwaj, A., Joshi, P. K., \& Ganju, A. (2015). High resolution DEM generation for complex snow covered Indian Himalayan Region using ADS80 aerial push-broom camera: a first time attempt. Arabian Journal of Geosciences, 8(3), 1403-1414.

https://doi.org/10.1007/s12517-014-1299-9

Vaze, J., Teng, J., \& Spencer, G. (2010). Impact of DEM accuracy and resolution on topographic indices. Environmental Modelling and Software, 25(10), 1086-1098. https://doi.org/10.1016/j.envsoft.2010.03.014

Wilson, J. P. (2012). Digital terrain modeling. Geomorphology, 137(1), 107-121. https://doi.org/10.1016/j.geomorph.2011.03.012 